\title{
The role of ultrasound in determining the amount of pleural effusion
}

\author{
Xiao-Ning Liang ${ }^{1}$, Chao-Yang Lv ${ }^{1}$, Huan-Zhong Shi ${ }^{2}$, Rui-Jun Guo ${ }^{1}$, Shuo Li $^{1}$ \\ ${ }^{1}$ Departments of Ultrasound Medicine, Beijing Chaoyang Hospital, Capital Medical University, Beijing, China; ${ }^{2}$ Departments of Respiratory, Beijing \\ Chaoyang Hospital, Capital Medical University, Beijing, China \\ Contributions: (I) Conception and design: XN Liang, CY Lv, S Li; (II) Administrative support: RJ Guo, S Li; (III) Provision of study materials or \\ patients: HZ Shi; (IV) Collection and assembly of data: XN Liang, CY Lv, HZ Shi; (V) Data analysis and interpretation: XN Liang, CY Lv, RJ Guo, \\ S Li; (VI) Manuscript writing: All authors; (VII) Final approval of manuscript: All authors. \\ Correspondence to: Rui-Jun Guo, MD; Shuo Li, MD. Departments of Ultrasound Medicine, Beijing Chaoyang Hospital, Capital Medical University, \\ North Road 8, Gongti, Beijing 100020, China. Email: guodaoshi@126.com; lishuo880809@126.com.
}

Background: There is no standardized system to evaluate pleural effusion size on ultrasound (US). We aimed to explore the role of US in determining the amount of pleural effusion, with an attempt to provide evidence for clinical efficacy evaluation and treatment program selection.

Methods: A total of 98 patients undergoing thoracoscopy at our center were enrolled in this study. The patients take a sitting position, then the maximum depths of the pleural effusion by US at the subscapular line, posterior axillary line, midaxillary line, anterior axillary line, and midclavicular line, as well as the maximum thickness of the pleural effusion at the subscapular line, were measured before pleural effusion drainage. Then, the corresponding values in the lateral position were also measured. The relationships between the actual pleural effusion amounts and the measurements at these lines were analyzed using the multivariate linear regression model (MLRM).

Results: The regression equation of the group with a pleural effusion amount of $500-1,000 \mathrm{~mL}$ in the sitting position showed statistical significance $(\mathrm{P}=0.001)$. The $\mathrm{P}$ values of the maximum depths at the subscapular line $\left(\mathrm{X}_{1}\right)$ and midclavicular line $\left(\mathrm{X}_{5}\right)$ and the maximum thickness at the subscapular line $\left(\mathrm{X}_{6}\right)$ were below 0.05 . Thus, a final model was established using $\mathrm{X}_{1}, \mathrm{X}_{5}$, and $\mathrm{X}_{6}$ as the independent variables.

Conclusions: The combination of US examination and MLRM enables the quantitative determination of pleural effusion.

Keywords: Pleural effusion; ultrasound (US); logistic regression

Submitted Mar 31, 2021. Accepted for publication Jun 15, 2021.

doi: 10.21037/atm-21-2214

View this article at: https://dx.doi.org/10.21037/atm-21-2214

\section{Introduction}

Along with the development of medical imaging techniques, ultrasonography (US) has a much wider range of applications. Its functions have evolved from checking a single system/viscera to examining multiple systems, from two-dimensional (2D) imaging to 4D imaging (and even automated breast volume scanning at the coronal plane), and from single B-type US to acoustic radiation force impulse imaging $(1,2)$. US is rapid, easy to perform, non- invasive, and repeatable, and can provide real-time images. Its role in observing pleural effusion has been widely recognized in clinical settings (3). It has been reported that US can also be applied for quantifying pleural effusion. However, the estimated results have often differed, and no uniform calculation method has been available (4). In clinical practice there are pleural effusions that, depending on both the volume and the clinical conditions, should not be drained, the expiratory interpleural distance measured or 

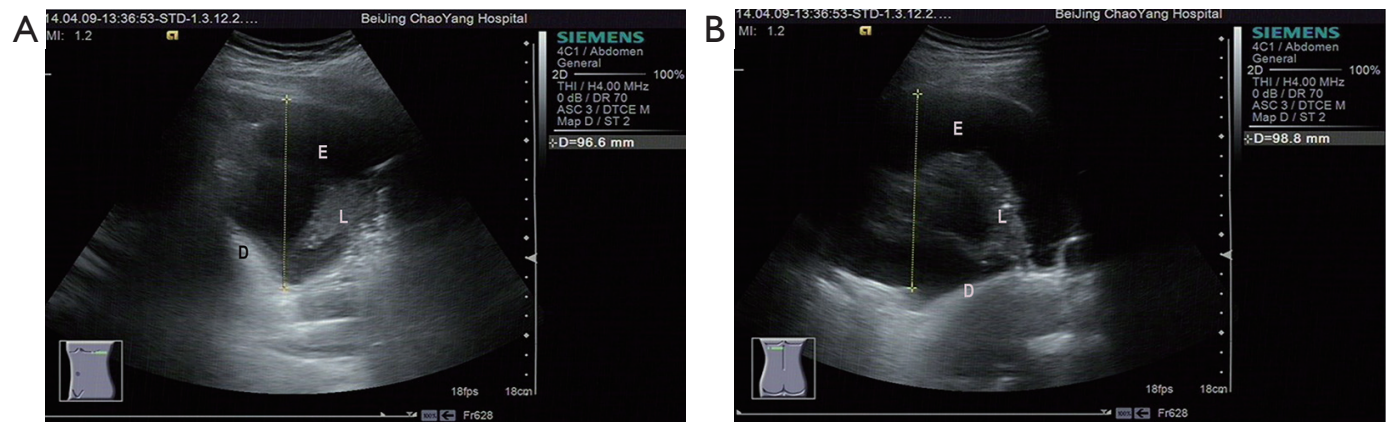

Figure 1 Measured pleural effusion depth at the midaxillary line (A) and subscapular line (B) in the sitting position. Massive effusion (E) causing atelectasis of the lung $(\mathrm{L})$ by compression. The diaphragm (D) becomes clearly visible through the effusion.

a standardized grading system for quantification of pleural effusions but not exactly.

Thoracoscopy is often used to diagnose pleural effusion, as it can remove excess fluid in the pleural cavity and thus obtain the actual effusion amount (5). Therefore, in our current study, we enrolled 85 patients undergoing thoracoscopy to evaluate the role of US in measuring pleural effusion, in particular its maximum thickness. Also, we carried out linear regression analysis of the relationship between the US measurements and the actual amounts, with an attempt to propose the calculation formula and the efficacy evaluation criteria during the determination of pleural effusion by US.

We present the following article in accordance with the STARD reporting checklist (available at https://dx.doi. org/10.21037/atm-21-2214).

\section{Methods}

\section{Subjects}

In this retrospective study, a total of 98 patients [50 men and 48 women aged $19-62$ years $(54 \pm 9.5$ years)] undergoing thoracoscopy at our hospital from August 2013 to July 2014 were enrolled. They were found to have pleural effusion during routine health check-ups. Critically ill patients and those who could not cooperate during the study were excluded. Patients with spaced or encapsulated pleural effusion were also ruled out. This study was conducted in accordance with the Declaration of Helsinki (as revised in 2013) (6). The study was approved by Ethics Committee of Beijing Chaoyang Hospital, Capital Medical University (No. 2019-KE-195) and informed consent was taken from all individual participants.

\section{Instrument and methods}

US was performed with an ACUSON S2000 ${ }^{\mathrm{TM}}$ ultrasound system (Siemens, Berlin, Germany) using a 4 C 1 convex array probe at a frequency of 3.0-4.5 MHz. The patients were asked to take a sitting position before the thoracoscopy. Also, they were asked to take a maximal inspiration during the US examination. With the intercostal spaces as ultrasonic windows, the US probe searched the anechoic zones from the head to the bottom of the lungs. Then, transverse scanning perpendicular to the chest wall was performed. The maximum depths of pleural effusion at the subscapular line, posterior axillary line, midaxillary line, anterior axillary line, and midclavicular line, as well as the maximum thickness of pleural effusion at the subscapular line, were measured (Figure 1). The patients were then asked to take a lateral position, and the same measurements at these five lines were performed. The pleural effusion puncture point at the deepest site of the subscapular line in the sitting position and the pleural cavity puncture point at the deepest site of the posterior axillary line in the lateral position were marked.

Internal echoes, spot-like, flocculent echoes of the pleural effusion, the presence or absence of separation, and the presence or absence of pleural thickening were observed by US.

\section{Statistical methods}

Statistical analysis was performed using the SPSS 17.0 software package. Measurement data are presented as $\bar{x} \pm s$. The relationships between the actual pleural effusion amounts and US measurements were analyzed using the multivariate logistic regression model (MLRM), where: 
Table 1 Mean maximum depths at different body surface marking lines in the sitting and lateral positions

\begin{tabular}{|c|c|c|c|c|c|c|}
\hline $\begin{array}{l}\text { Pleural effusion } \\
\text { amount (mL) }\end{array}$ & Subscapular line & $\begin{array}{l}\text { Posterior axillary } \\
\text { line }\end{array}$ & Midaxillary line & $\begin{array}{l}\text { Anterior axillary } \\
\text { line }\end{array}$ & $\begin{array}{c}\text { Midclavicular } \\
\text { line }\end{array}$ & $\begin{array}{l}\text { Subscapular line } \\
\text { (thickness) }\end{array}$ \\
\hline \multicolumn{7}{|l|}{ Sitting position } \\
\hline $500-1,000$ & $8.322 \pm 0.773$ & $7.931 \pm 1.362$ & $7.780 \pm 1.660$ & $7.945 \pm 1.434$ & $7.218 \pm 1.428$ & $5.543 \pm 1.122$ \\
\hline$<500$ & $6.042 \pm 1.572$ & $4.938 \pm 0.892$ & $6.996 \pm 1.779$ & $5.521 \pm 1.049$ & $5.167 \pm 0.981$ & \\
\hline $500-1,000$ & $8.322 \pm 0.773$ & $7.931 \pm 1.362$ & $7.780 \pm 1.660$ & $7.945 \pm 1.434$ & $7.218 \pm 1.428$ & \\
\hline$>1,000$ & $10.260 \pm 3.107$ & $11.260 \pm 2.367$ & $11.593 \pm 2.512$ & $10.167 \pm 2.142$ & $10.710 \pm 2.652$ & \\
\hline
\end{tabular}

$\mathrm{Y}$ was the actual pleural effusion amount, $\mathrm{X}_{1}$ was the maximum depth of pleural fluid at the subscapular line in sitting position (for lateral position, $\mathrm{X}_{7}$ ), $\mathrm{X}_{2}$ was that at the posterior axillary line (for lateral position, $\mathrm{X}_{8}$ ), $\mathrm{X}_{3}$ was that at the midaxillary line (for lateral position, $\mathrm{X}_{9}$ ), $\mathrm{X}_{4}$ was that at the anterior axillary line (for lateral position, $\mathrm{X}_{10}$ ), and $\mathrm{X}_{5}$ was that at the midclavicular line (for lateral position, $X_{11}$ ). In addition, $X_{6}$ was the maximum thickness at the subscapular line (it could not be accurately measured in lateral position).

A logistic regression model was established based on the nature of the pleural fluid and the US image features, where: $\mathrm{Y}$ was the nature of the pleural fluid ( $0=$ transudates, $1=$ exudates); $X_{1}$ was separation $(0=$ absent, $1=$ present $)$; $\mathrm{X}_{2}$ was echo of pleural effusion $(0=$ no echo, $1=$ spot-like echoes, $2=$ flocculent echoes); $X_{3}$ was pleural thickness $(0=$ absent, $1=$ present $) ; X_{4}$ was transparency $(0=$ clear, $1=$ cloudy); $X_{5}$ was color $(0=$ yellowish green, $1=$ reddish brown). The regression equation was then established. $\mathrm{P} \leq 0.05$ was considered statistically significant.

\section{Results}

\section{Thoracoscopic findings}

Of these 98 patients who had undergone thoracoscopy, the pleural effusion amount was $500-1,000 \mathrm{~mL}$ in 44 cases, less than $500 \mathrm{~mL}$ in 24 cases, and more than $1,000 \mathrm{~mL}$ in 30 cases.

\section{US findings}

Each surface marking of the maximum depths of pleural effusion in sitting and lateral positions is shown in Table 1. The pleural fluid total protein was detected, and if the total protein was greater than $25 \mathrm{~g} / \mathrm{L}$, the fluid was an exudate. If the protein was less than $25 \mathrm{~g} / \mathrm{L}$, the fluid was a transudate. Among all patients, 68 patients had exudates and 30 patients had transudates, and the detailed results of US examinations are shown in Table 2.

\section{Results of MLRM analysis}

The regression equations for the pleural effusion $<500 \mathrm{~mL}$ group $(\mathrm{F}=0.142, \mathrm{P}=0.988)$ and the $>1,000 \mathrm{~mL}$ group $(\mathrm{F}=1.533, \mathrm{P}=0.212)$ showed no statistical significance. Only the regression equation of the group with a pleural effusion amount of $500-1,000 \mathrm{~mL}$ in the sitting position had statistical significance ( $\mathrm{F}=4.866, \mathrm{P}=0.001$; Table 3).

The $t$-test for each regression coefficient showed that the $\mathrm{P}$ values for maximum depths at the subscapular line $\left(\mathrm{X}_{1}\right)$ $(\mathrm{t}=3.810, \mathrm{P}=0.001)$ and midclavicular line $\left(\mathrm{X}_{5}\right)(\mathrm{t}=-2.061$, $\mathrm{P}=0.046)$ and the maximum thickness at the subscapular line $\left(\mathrm{X}_{6}\right)(\mathrm{t}=2.827, \mathrm{P}=0.008)$ were all less than 0.05 and could therefore be used as independent variables in MLRM using the following equation:

$$
\mathrm{Y}=54.171 \mathrm{X}_{1}-16.405 \mathrm{X}_{5}+27.477 \mathrm{X}_{6}
$$

According to the standardized residuals histogram, the standardized residuals of these measurements were normally distributed (Figure 2). According to the normal P-P plot of regression standardized residual, the points in the graph were basically located in one straight line. Thus, the equation was proven to be statistically significant (Figure 3).

The pleural effusion drainage amount could be estimated 

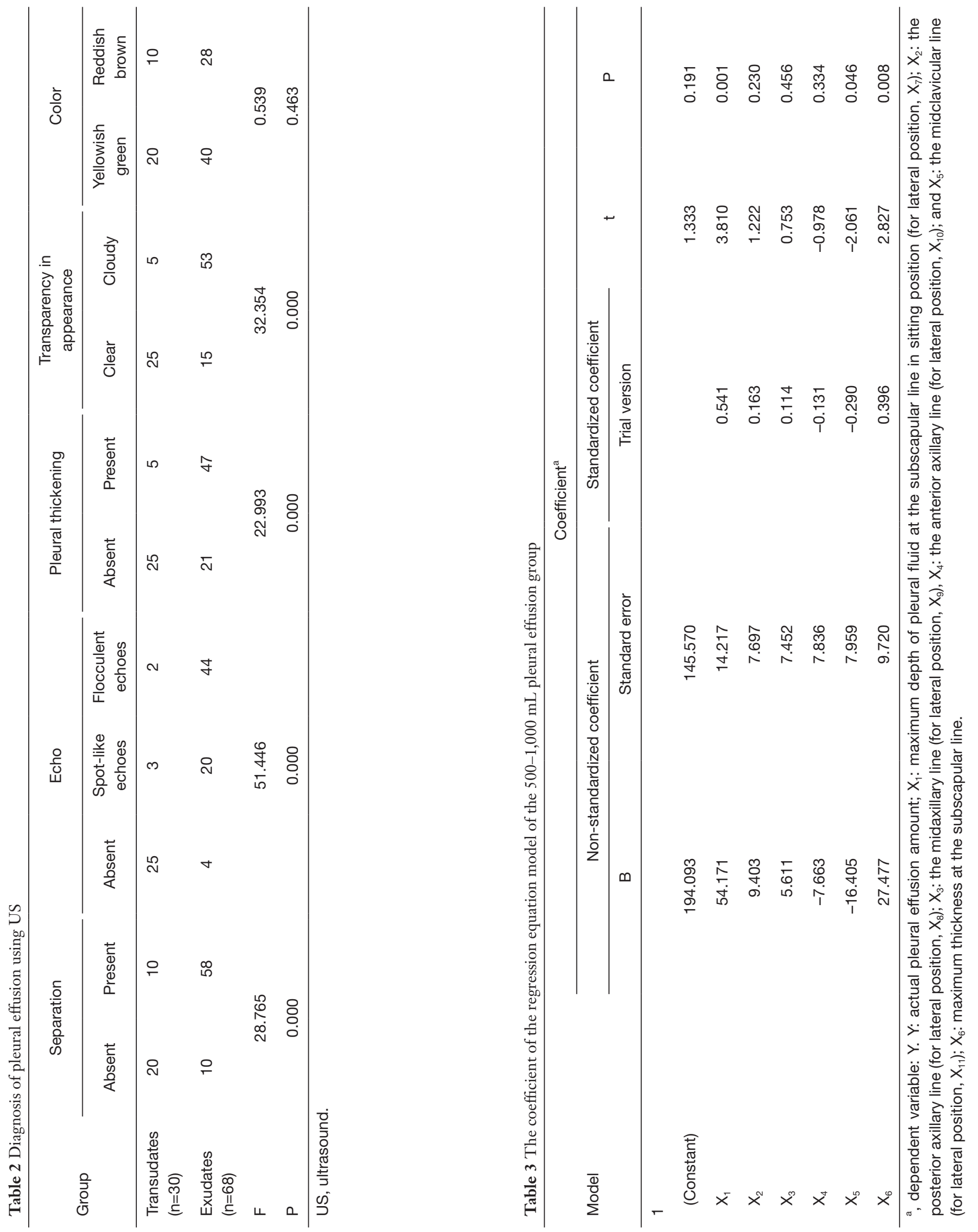


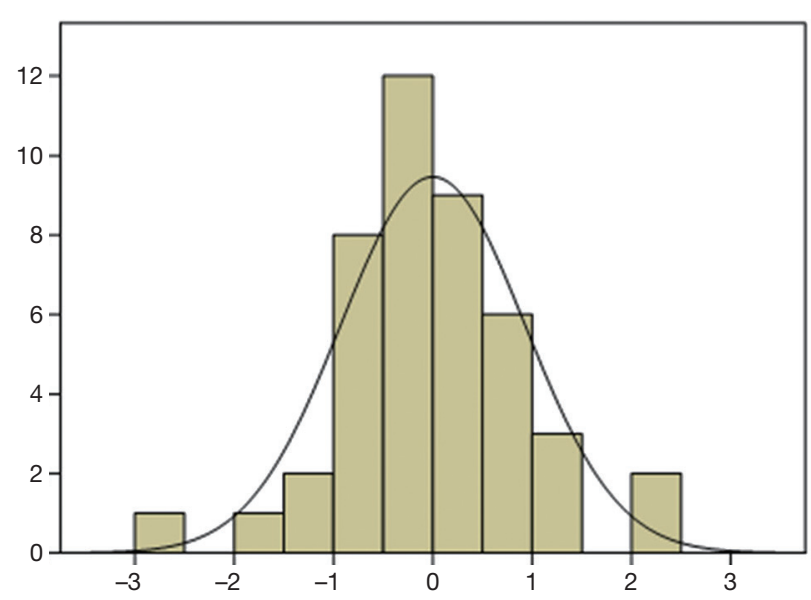

Figure 2 The standardized residuals histogram of the $500-1,000 \mathrm{~mL}$ pleural effusion group (the residuals obey normal distribution, the abscissa is the regression standardized residual and the ordinate is the frequency, mean: 1.43 E. 15 , standard deviation: $0.928, \mathrm{~N}=44$, dependent variable: Y).

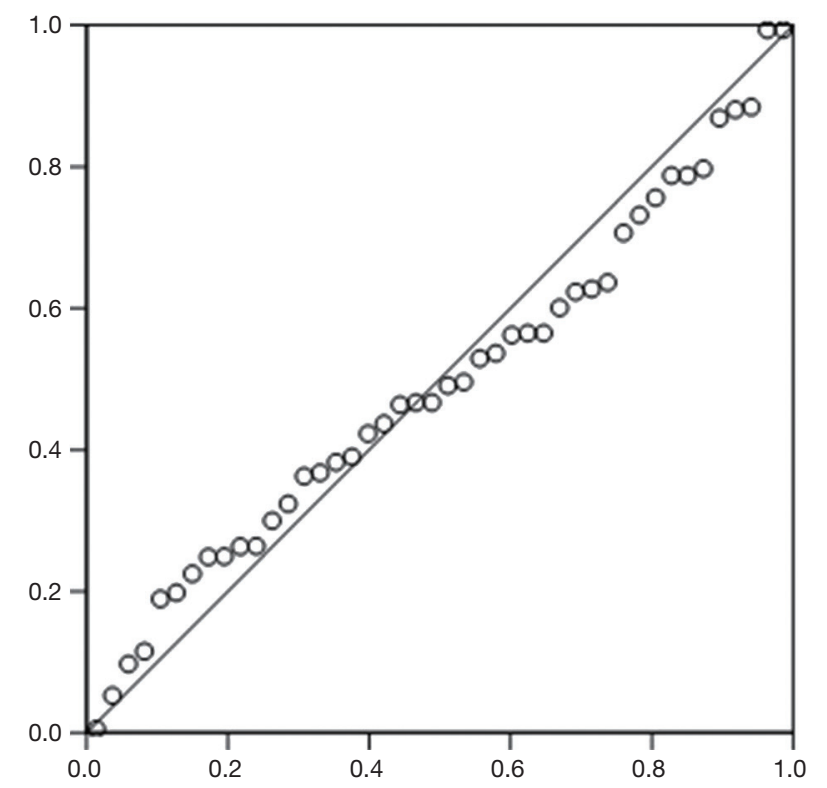

Figure 3 The normal P-P plot of regression standardized residuals (dependent variable: $\mathrm{Y}$, independent variables for the cumulative probability, the abscissa is the observed cumulative feasibility and the ordinate is the expected cumulative feasibility).

in accordance with the maximum depth of pleural effusion measured at the subscapular line and the maximum thickness measured at the subscapular line by US.

In the 44 patients with a pleural effusion amount of
$500-1,000 \mathrm{~mL}$, the agreement rate of the pleural effusion drainage amount was $84.1 \%(37 / 44)$.

The regression equations for the pleural effusion with exudate and transudate are shown in Table 4.

Binary logistic regression analysis was performed with exudates and transudates as the dependent variables and the above characteristics as the independent variables, and the results are shown in Table 4. Pleural thickening, transparency, and echo can be used as independent variables to establish the model $(\mathrm{P}=0.034)$, and the equation for the model was as follows:

$$
\operatorname{Logit}(\mathrm{P})=-3.185+2.746 \mathrm{X}_{2}+2.464 \mathrm{X}_{3}+2.475 \mathrm{X}_{4}
$$

The G-test was used in the logistic regression with a G-value of 11.028 , and a $P$ value of 0.004 . Using this logistic regression model, patient prognosis was predicted by $\mathrm{P}$ values calculated in logistic regression, and the predictive accuracy was $76.2 \%$. The area under the receiver operating characteristic (ROC) curve (AUC) for pleural thickening was 0.762 (95\% CI: $0.660-0.864, \mathrm{P}=0.000$ ), the sensitivity was $69.1 \%$, and the specificity was $83.3 \%$. The AUC for transparency was 0.806 (95\% CI: $0.710-0.903$, $\mathrm{P}=0.000$ ), the sensitivity was $77.9 \%$, and the specificity was $83.3 \%$. The AUC for echo was 0.910 (95\% CI: 0.838-0.981, $\mathrm{P}=0.000$ ), the sensitivity was $94.1 \%$, and the specificity was $83.3 \%$ (Figure 4).

\section{Discussion}

The diagnosis of pleural effusion is typically based on $\mathrm{X}$-ray, US, and chest CT $(6,7)$. US is superior to X-ray in terms of sensitivity because it can detect smaller amount of pleural effusion and measure local pleural thickness (8). US is also superior to chest CT in detecting simple pleural effusion and in determining the puncture point of pleural effusion during puncture drainage (9). For encapsulated pleural effusion in particular, US can provide the optimal auxiliary clinical puncture site (10). In our current study, US positioning was required before thoracoscopy to determine the optimal puncture point.

Since the distribution of intrathoracic liquid depends on the position of patients, a more standardized method for estimating pleural effusion is necessary. To ensure the accuracy of repeated measurements, we used the sitting position during the US procedures, although the supine position has also been reported by $\mathrm{Li}$ et al. (11). In $\mathrm{Li}$ et al.'s study, the free liquids were accumulated at the back when 
Table 4 Univariate and multivariate regression analysis in pleural effusion with exudate and transudate

\begin{tabular}{|c|c|c|c|c|c|c|c|c|c|c|}
\hline \multirow{2}{*}{$\begin{array}{l}\text { Pleural } \\
\text { effusion }\end{array}$} & \multicolumn{5}{|c|}{ Univariate } & \multicolumn{5}{|c|}{ Multivariate } \\
\hline & B & $\operatorname{Exp}(B)$ & Lower & Upper & $P$ & B & $\operatorname{Exp}(B)$ & Lower & Upper & $\mathrm{P}$ \\
\hline Separation & -2.451 & 0.086 & 0.031 & 0.237 & 0.000 & 0.618 & 1.855 & 0.242 & 14.230 & 0.552 \\
\hline Echo & -4.924 & 0.007 & 0.001 & 0.043 & 0.000 & 2.746 & 15.573 & 3.446 & 69.977 & 0.000 \\
\hline Transparency & -2.872 & 0.057 & 0.019 & 0.173 & 0.000 & 2.457 & 11.664 & 1.843 & 73.835 & 0.009 \\
\hline Color & -0.336 & 0.714 & 0.290 & 1.756 & 0.464 & & & & & \\
\hline Constant & & & & & & -3.185 & 0.006 & - & - & 0.041 \\
\hline
\end{tabular}

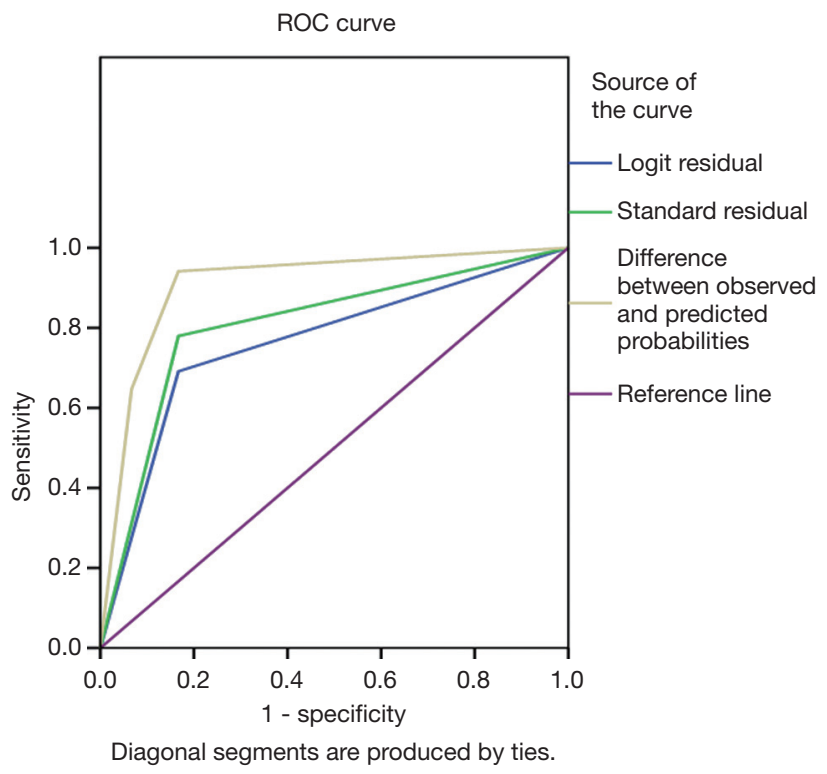

Figure 4 ROC curves for pleural thickening, transparency, and echo of pleural effusion. For pleural thickening, the AUC was 0.762 , 95\% CI: $0.660-0.864, \mathrm{P}=0.000$, sensitivity: $69.1 \%$, specificity: $83.3 \%$. For transparency, the AUC was $0.806,95 \%$ CI: $0.710-0.903, \mathrm{P}=0.000$, sensitivity: $77.9 \%$, specificity: $83.3 \%$. For echo, the AUC was 0.910, 95\% CI: 0.838-0.981, P=0.000, sensitivity: $94.1 \%$, specificity: $83.3 \%$. ROC, receiver operating characteristic; AUC, area under the ROC curve.

the patients were asked to take a supine position. Then the maximum thickness represented the actual pleural effusion amount. Therefore, the findings were quite different between our study and theirs.

In our study, US examination was applied to estimate the pleural effusion amount and compare that with the actual drainage amount. This study design is simpler than that reported by Goodlin et al., in which the marker dilution method was applied as the control data (12). In addition, MLRM analysis has been widely used in a variety of fields including epidemiology, discriminant analysis of clinical diagnostic criteria, and treatment evaluation (13). As seen from the residual plot, the absolute values of the residuals were relatively small and the depicted points were randomly distributed alongside the horizontal axis. These well-fitting regression model results indicated that $\mathrm{X}$ was significantly correlated with $\mathrm{Y}$. These findings further confirmed that the US method was accurate and reliable. This technique is also simple, less time-consuming, non-invasive, and can therefore be well accepted by patients.

Our study also found that pleural effusion at an amount of 500-1,000 mL was significantly correlated with the maximum depth and maximum thickness at the subscapular line but not with the maximum depths at other lines. In contrast, Shen et al. found that the pleural effusion amount was positively correlated with the maximum depth under US but was not significantly correlated with the number of rib spaces, number of longitudinal zones, and sequence of drainage (14). The maximum thickness was employed as a coefficient in our equation because the maximum depths at all these five lines showed no statistical significance in patients with a pleural effusion amount of smaller than $500 \mathrm{~mL}$ or between 500 and $1,000 \mathrm{~mL}$. In addition, we divided the actual pleural effusion amount into three groups to make the estimation results more accurate. According to the standardized residuals histogram, the standardized residuals of these measurements were normally distributed, 
which demonstrated the statistical significance of the equation. Our study was limited by its relatively small size. Also, the actual pleural effusion amount affects the depth of US measurement. If the pleural effusion amount is too small or too large, the measurement for the depth will yield an accurate result, which further affects the accuracy of the equation. Further study is warranted to confirm whether the US measurement equation is feasible for patients with a small/large amount of pleural effusion.

In terms of the pathological basis of pleural thickening, benign pleural thickening is mainly caused by inflammation and allergies, and its main pathological changes are pleural exudative fibrous tissue hyperplasia and tuberculous granulation tissue hyperplasia (13). In malignant pleural thickening, the pathological changes are corresponding pleural changes caused by the erosion and destruction of malignant tumors originating from the heart, lung, mediastinum, and other distant organs $(4,14)$. However, both benign and malignant pleural thickening cause corresponding inflammation and an allergic response of the pleura, which lead to pleural thickening and pleural effusion. This is consistent with our results showing that there was a correlation between exudative pleural effusion and pleural thickening.

US-based measurements cannot be applied in all patients with pleural effusion. For instance, in patients with pleural effusion due to a specific inflammation (e.g., tuberculous pleurisy), tissue adhesions are often present in the pleural cavity and the pleural effusion is often encapsulated. Under such conditions, US measurement often cannot yield the required data $(15,16)$. Second, although US is a noninvasive technique, critically ill patients with malignant pleural effusion may not be able to tolerate the sitting position for extended periods. Therefore, this approach is not feasible for patients with severe hydrothorax.

\section{Acknowledgments}

Funding: None.

\section{Footnote}

Reporting Checklist: The authors have completed the STARD reporting checklist. Available at https://dx.doi. org/10.21037/atm-21-2214

Data Sharing Statement: Available at https://dx.doi. org/10.21037/atm-21-2214
Conflicts of Interest: All authors have completed the ICMJE uniform disclosure form (available at https://dx.doi. org/10.21037/atm-21-2214). The authors have no conflicts of interest to declare.

Ethical Statement: The authors are accountable for all aspects of the work in ensuring that questions related to the accuracy or integrity of any part of the work are appropriately investigated and resolved. This study was conducted in accordance with the Declaration of Helsinki (as revised in 2013). The study was approved by Ethics Committee of Beijing Chaoyang Hospital, Capital Medical University (No. 2019-KE-195) and informed consent was taken from all individual participants.

Open Access Statement: This is an Open Access article distributed in accordance with the Creative Commons Attribution-NonCommercial-NoDerivs 4.0 International License (CC BY-NC-ND 4.0), which permits the noncommercial replication and distribution of the article with the strict proviso that no changes or edits are made and the original work is properly cited (including links to both the formal publication through the relevant DOI and the license). See: https://creativecommons.org/licenses/by-nc-nd/4.0/.

\section{References}

1. Moore CL, Copel JA. Point-of-care ultrasonography. N Engl J Med 2011;364:749-57.

2. Cosgrove DO. Evolution of ultrasonography since the 1970s. Ultrasound Med Biol 2017;43:2741-2.

3. Hirsch A, Ruffie P, Nebut M, et al. Pleural effusion: laboratory tests in 300 cases. Thorax 1979;34:106-12.

4. Qureshi NR, Gleeson FV. Imaging of pleural disease. Clin Chest Med 2006;27:193-213.

5. Loddenkemper R. Thoracoscopy--state of the art. Eur Respir J 1998;11:213-21.

6. Hansell DM, Lynch DA, McAdams HP, et al. Imaging of diseases of the chest. Philadelphia: Mosby Elsevier, 2013.

7. Schwartz DS, Reyes-Mugica M, Keller MS. Imaging of surgical diseases of the newborn chest. Intrapleural mass lesions. Radiol Clin North Am 1999;37:1067-78, v.

8. McGrath EE, Anderson PB. Diagnosis of pleural effusion: a systematic approach. Am J Crit Care 2011;20:119-27; quiz 128.

9. $\mathrm{Hu} \mathrm{C}$ and Guan Z. Ultrasonic diagnosis and analysis of 360 cases of pleural effusion. Modern Journal of Integrated Chinese Traditional and Western Medicine 
2004;15:2049-50.

10. Xu D, Kong X. Comparison of the application of ultrasound-guide and non-ultrasound-guided pleural effusion puncture. Sichuan Medical Journal 2012;33:2030-1.

11. Li YH, Sun SQ. Effect of hypotonic medium on expression of aquaporin-4 in astrocytes. Zhonghua Yi Xue Za Zhi 2004;84:496-501.

12. Goodlin RC, Anderson JC, Gallagher TF. Relationship between amniotic fluid volume and maternal plasma volume expansion. Am J Obstet Gynecol 1983;146:505-11.

13. Tsai TH, Yang PC. Ultrasound in the diagnosis and management of pleural disease. Curr Opin Pulm Med

Cite this article as: Liang XN, Lv CY, Shi HZ, Guo RJ, Li S. The role of ultrasound in determining the amount of pleural effusion. Ann Transl Med 2021;9(12):972. doi: 10.21037/atm21-2214
2003;9:282-90.

14. Shen G, Song ST, Yang WW, et al. Clinical significance of using B-mode ultrasonography to determine the quantity of pleural fluid. Chinese Journal of Clinical Oncology and Rehabilitation 2004;11:57-9.

15. Moy MP, Levsky JM, Berko NS, et al. A new, simple method for estimating pleural effusion size on CT scans. Chest 2013;143:1054-9.

16. Xing P, Wu L, Zhang C, et al. Differentiation of benign from malignant thyroid lesions: calculation of the strain ratio on thyroid sonoelastography. J Ultrasound Med 2011;30:663-9. 